\title{
Ancient air caught by shooting stars
}

Ashes of ancient meteors recovered from a 2.7-billion-year-old lake-bed imply that the upper atmosphere was rich in oxygen at a time when all other evidence implies that the atmosphere was oxygen-free. SEE LETTER P.235

\section{KEVIN ZAHNLE \& ROGER BUICK}

$\mathrm{t}$ is a truth almost ${ }^{1}$ universally acknowledged that Earth's atmosphere before about 2.5 billion years ago had little or no free oxygen. The classic argument for anoxia on ancient Earth is that a distinct change occurred in the oxidation state of many surface rocks and minerals around the end of the Archaean eon $^{2}$ (which lasted from 4 billion to 2.5 billion years ago). A more recent argument is that a sudden, permanent change in the relative abundances of rare sulfur isotopes preserved in sediments also occurred at that time - a change that can be linked to differences in sulfur's atmospheric chemistry in the presence or absence of oxygen ${ }^{3}$. These arguments are strong. It therefore comes as a surprise that melted meteor fragments recovered from Archaean limestone indicate that the contemporaneous atmosphere above 75 kilometres was highly oxidized, as reported by Tomkins et al. ${ }^{4}$ on page 235 .

The authors recovered 60 micrometeorites 


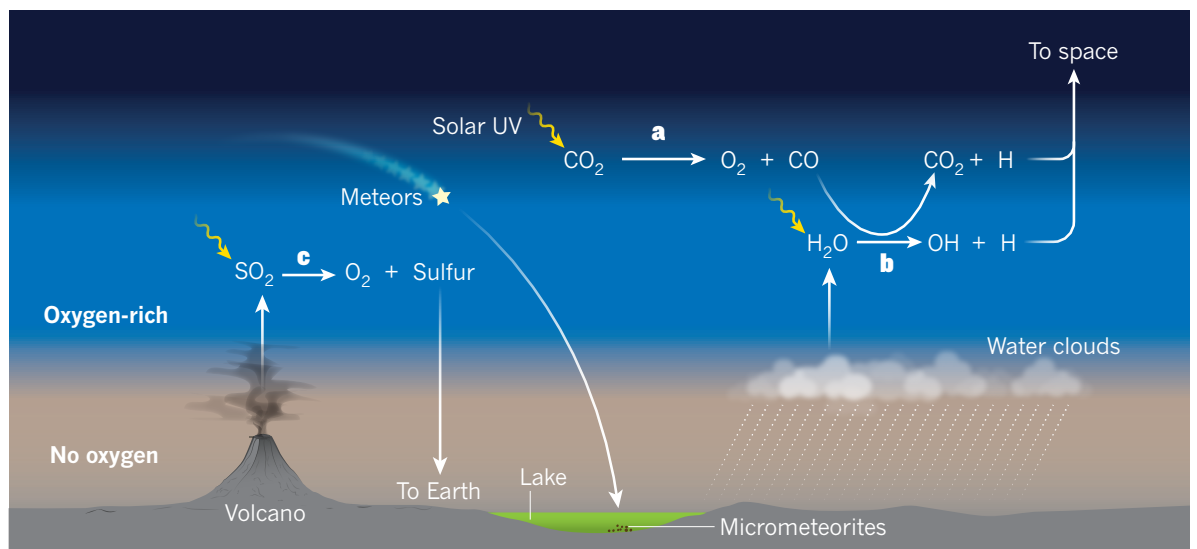

Figure 1 | Possible mechanisms of oxygen enrichment in the Archaean atmosphere. Tomkins et al. ${ }^{4}$ conclude that micrometeorites found in sedimentary limestone deposited 2.7 billion years ago were oxidized by their passage through an oxygen-rich upper atmosphere at a time when the lower atmosphere was anoxic. a, Oxygen could have formed in the upper atmosphere if carbon dioxide was split by solar ultraviolet radiation to form oxygen and carbon monoxide. However, the $\mathrm{CO}$ would have to have been removed to enrich the upper atmosphere in oxygen. $\mathbf{b}$, Water vapour (most of which is likely to have condensed in the lower atmosphere) could have split to form $\mathrm{OH}$ radicals and hydrogen atoms, so that the $\mathrm{OH}$ could react with $\mathrm{CO}$ to regenerate $\mathrm{CO}_{2}$. The hydrogen would have escaped to space, leaving oxygen behind. c, Alternatively, if sulfur dioxide from volcanoes was split by solar UV to form oxygen and sulfur particles, then the particles could have fallen to Earth's surface, leaving oxygen behind.

from 2.7-billion-year-old limestone in the Pilbara region of Western Australia. Micrometeorites are the surviving bits of meteors that were too small to burn up as shooting stars in the atmosphere, and are typically tens of micrometres in diameter. All but one of the Pilbara micrometeorites were originally sand-sized grains of iron and nickel alloy. Of the 11 studied in detail, 9 are composed of an oxidized mineral called magnetite $\left(\mathrm{Fe}_{3} \mathrm{O}_{4}\right)$ and retain a distinctive morphology that indicates fast cooling. The other two retain some of the original metal and wüstite ( $\mathrm{FeO})$, an iron oxide that occurs in meteorite fusion crusts. Nearly as remarkable as their existence is that there is nothing otherwise remarkable about them they look like, and are as oxidized as, the iron micrometeorites that fall to Earth today ${ }^{5}$.

Tomkins et al. argue that the micrometeorites look modern because the air above $75 \mathrm{~km}$ was roughly as oxidized during the Archaean as it is today, and back this up using a model of meteor physics and chemistry tuned for modern Earth. The model shows that the air in that region needed to be oxygen-rich for it to oxidize all the iron to magnetite as it slowed the meteor's flight. If, however, the chemical reaction continued for a little longer than was modelled, it might have sufficed for the air to be less oxic. Carbon dioxide could have acted as an alternative oxidant (see Extended Data Fig. 5 of the paper ${ }^{4}$ ), although the kinetics for oxidation with $\mathrm{CO}_{2}$ are less favourable than with oxygen.

The idea that an oxygen-rich upper atmosphere sat on top of an anoxic lower atmosphere poses a serious challenge to atmospheric modellers. Models predict ${ }^{6}$ that oxygen can be abundant at extremely high altitudes in otherwise anoxic atmospheres, but because the oxygen comes from $\mathrm{CO}_{2}$ that was split by sunlight (photolysis), it is balanced by a stoichiometric complement of carbon monoxide (Fig. 1). Overall, the resulting gas mixture would be no more oxidizing than $\mathrm{CO}_{2}$ itself.

To create a local superabundance of oxygen from $\mathrm{CO}_{2}$, the $\mathrm{CO}$ must be preferentially removed. There is no obvious way to do this. Some other molecule is therefore required that can be split into oxygen and a chemically reduced species that can be easily removed. One possible candidate is sulfur dioxide $\left(\mathrm{SO}_{2}\right)$ from volcanoes. This gas can be split by sunlight into oxygen and elemental sulfur, which can condense to form particles that fall to Earth, leaving oxygen behind. Isotopes in sedimentary rock indicate that elemental sulfur did fall from the skies during the Archaean ${ }^{7}$, which makes $\mathrm{SO}_{2}$ an attractive candidate.

The other obvious candidate is water vapour, which can be split by sunlight to free hydrogen atoms that escape to space, leaving oxygen behind. Water can do double duty here: the hydroxyl $(\mathrm{OH})$ radicals generated by water photolysis react with $\mathrm{CO}$ to put $\mathrm{CO}_{2}$ back together again, freeing more hydrogen atoms. If the hydrogen atoms escape to space quickly enough, then the top of the atmosphere can become rich in oxygen. This is why Mars has more oxygen than $\mathrm{CO}$ in its atmosphere.

But today, water is cold-trapped in Earth's lower atmosphere and the upper atmosphere is very dry. For water vapour to have reached the upper atmosphere during the Archaean, either the cold trap must have been warmer than it is today, or the atmosphere must have been thinner, which would have made the cold trap less effective ${ }^{8}$. Evidence ${ }^{9}$ that atmospheric pressure was less than half of what it is today - and perhaps much less - has been found in rocks of almost identical age to those hosting the oxidized micrometeorites. The micrometeorites might, therefore, be evidence of a thinner atmosphere.

The Pilbara micrometeorites are not the only preserved probes of the Archaean atmosphere. Several thick beds of impact-generated spherules - rounded bodies formed from the molten ejecta of meteorite impacts - provide hints about the atmosphere they fell through ${ }^{10}$. The Archaean spherule beds are analogous to the thinner spherule layers broadcast worldwide by the Chicxulub impact that killed the dinosaurs. One distinction between the Chicxulub and the Archaean spherules is that the latter were formed under markedly more reducing conditions, which has been interpreted to mean that the Archaean atmosphere contained no more than $0.01 \%$ oxygen ${ }^{10}$. The spherules probably last reacted with air when they re-entered the atmosphere as meteors typically reaching a height of between 30 and $50 \mathrm{~km}$, judging from the spherules' size (about a millimetre in diameter). In other words, the air last sampled by the spherules would have been between the air at Earth's surface and that sampled by the micrometeorites.

It is remarkable that objects as small as the micrometeorites survived intact for 2.7 billion years. The survival of wüstite is particularly unusual - this mineral is not normally seen near Earth's surface - and is crucial to the authors' interpretation of these minuscule objects as being extraterrestrial. However, the micrometeorites were deposited in a highly unusual environment: the Tumbiana Formation.

This rock formation was once a system of lakes, and the lake in which the micrometerorites were found was highly alkaline ${ }^{11}$, as indicated by its extremely high abundance of heavy nitrogen isotopes ${ }^{12}$. Wüstite has low solubility under such $\mathrm{pH}$ conditions ${ }^{13}$, and would have been especially insoluble if the bottom waters of the lake and the pore waters in the buried sediments were anoxic. Such conditions are rarely encountered in the geological record, which means that the Pilbara micrometeorites might be a one-off discovery. This would be unfortunate, because the structure, pressure and vertical composition of the ancient atmosphere are fiendishly difficult things to determine. But one can wish upon a shooting star.

Kevin Zahnle is in the Space Science Division, NASA Ames Research Centre, Moffett Field, California 94035-1000, USA. Roger Buick is in the Department of Earth \& Space Sciences, and in the Astrobiology Program, University of Washington, Seattle, Washington 98195-1310, USA.

e-mails:kevin.j.zahnle@nasa.gov;

buick@ess.washington.edu

1. Ohmoto, H. Geochem. News 93, 12-13, 26-27 (1997),

2. Holland, H. D. Geochem. News 100, 20-22 (1999).

3. Farquhar, J., Bao, H. \& Thiemens, M. Science 289, 756-758 (2000).

4. Tomkins, A. G. et al. Nature 533, 235-238 (2016) 
5. Genge, M. J., Engrand, C., Gounelle, M. \& Taylor, S. Meteor. Planet. Sci. 43, 497-515 (2008).

6. Zahnle, K., Claire, M. \& Catling, D. Geobiology 4, 271-283 (2006).

7. Pavlov, A. A. \& Kasting, J. F. Astrobiology 2, 27-41 (2002).
8. Wordsworth, R. \& Pierrehumbert, R. Astrophys. J. 785, L20 (2014)

9. Som, S. M. et al. Nature Geosci. http://dx.doi. org/10.1038/ngeo2713 (2016)

10. Krull-Davatzes, A. E., Byerly, G. R. \& Lowe, D. R. Earth Planet. Sci. Lett. 296, 319-328 (2010).
11.Awramik, S. M. \& Buchheim, H. P. Precambr. Res. 174, 215-240 (2009).

12.Stüeken, E. E., Buick, R. \& Schauer, A. J. Earth Planet. Sci. Lett. 411, 1-10 (2015).

13.Jang, J. H. \& Brantley, S. L. Environ. Sci. Technol. 43, 1086-1090 (2009). 